Grant-in-Aid for Scientific Research (S)

Real Estate Markets, Financial Crisis, and Economic Growth : An Integrated Economic Approach

Working Paper Series No.5

Separating the Age Effect from a Repeat Sales Index: Land and Structure Decomposition

SK Wong

KW Chau

K Karato

C Shimizu

December, 2013

HIT-REFINED PROJECT

Institute of Economic Research, Hitotsubashi University

Naka 2-1, Kunitachi-city, Tokyo 186-8603, JAPAN

Tel: +81-42-580-9145

E-mail: hit-tdb-sec@ier.hit-u.ac.jp

http://www.ier.hit-u.ac.jp/ifn/ 


\title{
Separating the Age Effect from a Repeat Sales Index: Land and Structure Decomposition
}

\author{
SK Wong* KW Chau ${ }^{\dagger}, \mathrm{K}$ Karato $^{\ddagger}, \mathrm{C} \mathrm{Shimizu}^{\S}$
}

December 10, 2013

\begin{abstract}
Summary
Since real estate is heterogeneous and infrequently traded, the repeat sales model has become a popular method to estimate a real estate price index. However, the model fails to adjust for depreciation, as age and time between sales have an exact linear relationship. This paper proposes a new method to estimate an age-adjusted repeat sales index by decomposing property value into land and structure components. As depreciation is more relevant to the structure than land, the property's depreciation rate should depend on the relative size of land and structure. The larger the land component, the lower is the depreciation rate of the property. Based on housing transactions data from Hong Kong and Tokyo, we find that Hong Kong has a higher depreciation rate (assuming a fixed structure-to-property value ratio), while the resulting age adjustment is larger in Tokyo because its structure component has grown larger from the first to second sales.
\end{abstract}

\section{Introduction}

A price index aims to capture the price change of products free from any variations in quantity or quality. When it comes to real estate, the core problem is that it is heterogeneous and infrequently traded. Mean or median price indices are simple to compute, but properties sold in one period may differ from those in another period. To overcome this problem, two regression-based approaches are used to construct a constant-quality real estate price index (Shimizu et al. (2010)).

One is the hedonic price model, which specifies the property attributes to be controlled and uses time dummies to capture price changes over time. This method is often employed when data on property attributes are readily available, although omission of unobserved attributes or unique features of a property could lead to estimation bias. The other approach is the repeat sales model advanced by Bailey, Muth and Nourse (1963). It controls for quality variations, including the uniqueness of each property, by tracking the price change

\footnotetext{
* The University of Hong Kong

$\dagger$ The University of Hong Kong

¥University of Toyama

$\S$ Correspondence: Chihiro Shimizu, Reitaku University \& The University of British Columbia, Kashiwa, Chiba 277-8686, Japan. E-mail: cshimizu@reitaku-u.ac.jp.
} 
of properties that have been sold twice. This method is most useful when repeat sales are abundant. ${ }^{1}$

The repeat sales model is sometimes challenged for making a fundamentally incorrect assumption: quality could change over time even for the same property. For example, a repeat sales index may wrongly capture the price increase of a property due to the addition of a bedroom. But this is not the failure of the repeat sales model. If the change is known, the repeat sales model can be easily modified to account for it (Bailey, Muth and Nourse, 1963, p.935). If the change is unknown, both the hedonic and repeat sales models would suffer from the same problem. The real issue concerning the repeat sales model is that it is incapable of controlling for depreciation:

"Unfortunately, a depreciation adjustment cannot be readily estimated along with the price index using our regression method... Assuming that properties depreciate at a constant rate per unit time, ... the $x$ matrix [regressors] is singular... In applying our model, therefore, additional information would be needed in order to adjust the price index for depreciation." (Bailey, Muth and Nourse, 1963, p.936).

Unlike any other quality change, the increase in age of a property is always identical to the time elapsed between two sales. Including both age and time differences in the repeat sales regression gives rise to perfect collinearity. Not only are the age and time effects inseparable, but estimation also becomes impossible. Therefore, in many applications, the depreciation problem is simply ignored, resulting in a repeat sales index that is biased downward.

Following Bailey, Muth and Nourse's (1963) suggestion, several attempts were made to find the "additional information" needed to solve the identification problem. Palmquist (1980) proposed a two-stage method: first obtain an independent estimate of the deprecation rate from the hedonic price model and then add it to back to the repeat sales index. Case and Quigley (1991), Hill, Knight, and Sirmans (1997), and Englund, Quigley and Redfearn (1998) offered a similar idea but combined the hedonic and repeat sales regressions into a hybrid model for joint estimation. In both cases, cross-sectional differences in property age serve as the additional information to identify the depreciation rate. Chau, Wong, and Yiu (2005) found another instrument to separate the age and time effects. They treated depreciation as a discounted cash flow problem and showed that for leasehold properties, the age effect varies inversely with real interest rates. They also proved that simply converting the age variable into dummies does not work. For instance, Cannaday, Munneke, and Yang (2005) had to drop two age dummies arbitrarily in order to avoid perfect collinearity, although a high degree of collinearity still remains. ${ }^{2}$

This paper proposes a new method to estimate an age-adjusted repeat sales index by

\footnotetext{
${ }^{1}$ Diewert(2007) summarized advantages and disadvantages in Repeat Sales measure and Hedonic measure. And, Shimizu et al. (2010) compared Hedonic Index, Traditional Repeat Sales Index, Case-Shiller type Repeat Sales Index, Age adjusted Repeat Sales Index and new type Hedonic Index or Rolling Window Hedonic Index using Tokyo data..

${ }^{2}$ Shimizu, Nishimura and Watanabe(2010) and Karato, Movshuk and Shimizu (2010) also proposed new estimation method to separate the age and time effects. Karato, Movshuk and Shimizu (2010) tried to separate age effect, time effect and cohort effect using semi -parametric approach; Generalized Additive Model or GAM.
} 
decomposing property value into land and structure components. ${ }^{3}$ The key idea is that depreciation is more relevant to the structure than land. Since a property is the sum of both components, its depreciation rate depends on the relative size of land and structure. The larger the land component, the lower is the depreciation rate of the property. Section 2 derives the relationship between the depreciation rate and a structure-to-property price ratio, and shows how the ratio can be used as additional information to separate the age effect from a repeat sales index. Moreover, similar to Chau, Wong, and Yiu (2005), the age effect is allowed to be non-linear by adopting a flexible functional form.

The proposed method is then used to estimate the repeat sales indices and depreciation rates for the housing markets in Hong Kong and Tokyo. While both are densely developed cities with high property prices, we expect them to have different deprecation patterns because the maintenance of condominiums (in particular the common areas) is a function of the institutions governing the rights and duties of unit owners. Specifically, buildings in Japan have better upkeep in order to withstand earthquakes and fulfill the relevant legal (Building Standards Law) and insurance requirements. Section 3 will present the data and estimation results. Section 4 will further check the robustness of the estimates using a hybrid and hedonic model. The last section is the conclusion.

\section{$2 \quad$ An age-adjusted repeat sales model}

Suppose property value $(P)$ is the sum of land value $(L)$ and structure value $(S){ }^{4}$ The value of a new property is:

$$
P(0)=L+S(0)
$$

where the number in brackets represents the building age. Aging reduces the value of the structure value but not the land. Therefore, $L$ is not a function of building age.

After A periods, the property reaches age $A$. Assuming a stable economy where $\mathrm{L}$ and $S(0)$ remain unchanged, the property value will decline solely due to aging:

$$
P(A)=L+S(0) \times(1-\delta \quad A)
$$

where $\delta$ is the depreciation rate of the structure. Equation 2 can be easily generalized to allow for a non-linear depreciation pattern. One way is to replace $A$ with a more flexible function $\mathrm{g}(A)$ :

$$
P(A)=L+S(0) \times[1-\delta g(A)]
$$

\footnotetext{
${ }^{3}$ Diewert and de Haan (2011) and Diewert and Shimizu (2013) proposed a new hedonic model to decompose the Land and Structure component.

${ }^{4}$ Thorsnes $(1997 ; 101)$ assumed that a related supply side model held instead of equation $(2)$. He assumed that housing was produced by a CES production function $H(L, K)=\left[\alpha L^{\rho}+\beta K^{\rho}\right]^{1 / \rho}$ where $K$ is structure quantity and $\rho \neq 0 ; \alpha>0 ; \beta>0$ and $\alpha+\beta=1$. He assumed that property value $V_{n}^{t}$ is equal to $p_{t} H\left(L_{n}^{t}, K_{n}^{t}\right)$ where $p_{t}, \rho, \alpha$ and $\beta$ are parameters to be estimated. However, Diewert's builder's model assumes that the production functions that produce structure space and that produce land are independent of each other.
} 
Take $g(A)=A \lambda$ as an example. $\delta$ represents the initial depreciation rate of the structure. The depreciation rate would rise with age if $\lambda>1$, decrease with age if $0<\lambda<1$, and remain at $\delta$ if $\lambda=1$.

According to Equation 3, as long as land value is not zero, the property would depreciate at a rate lower than the structure. Specifically, the depreciation rate of $P$ depends not only on $\delta$ but also on the ratio of new structure value to new property value:

$$
(P(A)-P(0)) /(P(0))=-S(0) / P(0) \delta g(A)
$$

Equation 4 has two important implications. First, given the same $\delta$ (e.g. building technology) for all structures, properties in a high land value area would depreciate more slowly than those in a low land value area. Second, even if the structure depreciates at a constant rate, the property's depreciation rate is likely to be time-varying because structure and land values do not move at the same pace. ${ }^{5}$ The property would depreciate more (less) when construction costs increase (decrease) faster than land costs.

The second implication provides us with a new perspective to resolve the perfect collinearity between age and time in the repeat sales method. This new perspective is different from the previous attempts that aimed to break down the linear relationship between age and time by introducing "error" to the age variable. For instance, Cannaday, Munneke, and Yang (2005) converted age into a set of dummy variables and dropped two such dummies to avoid perfect collinearity with time by making an arbitrary assumption that the depreciation rate is the same for certain ages. Our approach to the problem relies on the use of external information to disentangle the effects of age and time. Chau, Wong, and Yiu (2005) also followed this approach to derive the age effect as a function of real interest rates, but their model is more applicable to leasehold interests. This paper proposes a more general framework to separate the age and time effects based on the relative size of land and structure. The ratio of new structure value to new property value is the external information we rely upon.

To motivate our age-adjusted repeat sales model, we can start with a hedonic price equation and supplement it with the age term from Equation 4:

$$
\ln P_{i t}=X_{i} \beta+\mathbf{a}_{t}-\delta R_{t} g\left(A_{i t}\right)+\epsilon_{i t}
$$

where $P_{i t}$ is the price of property $i$ at time $t ; X_{i}$ is a vector of property attributes excluding building age; $\beta$ is a vector of the implicit price of the attributes; $\alpha_{t}$ is the property price index at time $t$; and $\epsilon_{i t}$ is a random error.

The third term on the right captures the age effect, where Rt is the ratio of construction cost to new property price at time $t$. The smaller the $R_{t}$, the larger the non-depreciable land component, hence the smaller the age effect on property prices. This generalizes the standard hedonic model, which assumes $R_{t}=1$.

\footnotetext{
${ }^{5}$ In general, the inelastic supply of land makes land value more volatile and more sensitive to economic shocks than building value.
} 
To allow for a non-linear depreciation pattern of the structure, the age function, $g\left(A_{i t}\right)$, adopts the Box-Cox transformation as shown in Equation $6 .^{6}$ If $\lambda=1$, the structure depreciates at a constant rate $\delta$. If $\lambda>1$, the structure depreciates faster as its age increases. If $\lambda<1$, the structure depreciates more slowly as its age increases. In all cases, $\delta$ is expected to be positive.

$$
g\left(A_{i t}\right)=\left(\frac{A_{i t}^{\lambda}-1}{\lambda}\right)
$$

Given that property $i$ is sold twice at time s and $t$ (where $t>s$ ) and there is no change in property attributes between the sales, our age-adjusted repeat sales model can be derived from the $(t-s)$ th difference of Equation 5 :

$$
\ln \left(\frac{P_{i t}}{P_{i s}}\right)=\left(\alpha_{t}-\alpha_{s}\right)-\delta\left[R_{t} g\left(A_{i t}\right)-R_{s} g\left(A_{i s}\right)\right]+\left(\epsilon_{i t}-\epsilon_{i s}\right)
$$

A key advantage of the repeat sales model is that it is less vulnerable to omitted variable bias - as long as the unobserved attributes do not change between sales, they will be cancelled out and do not affect estimation of the change in price index, $\alpha_{t}-\alpha_{s}$. Assuming $\epsilon_{i t}-\epsilon_{i s}$ is normally distributed, the parameters in Equation 7 can be estimated by the maximum likelihood method. We call our new model in Equation 7 the "Age-R model", which spells out the key feature that building age is interacted with the structure-to-property value ratio. The traditional repeat sales model without the age term (called the BMN model) will also be estimated and compared against the Age-R model.

Again, if the Age-R model is correct, $\delta$ should be positive. Even if the structure depreciates at a constant rate (i.e. $\lambda=1$ ), the Age-R model is still free from perfect collinearity because the structure-to-property value ratio is unlikely to be fixed over time, especially upon the arrival of economic shocks. A time-varying structure-to-property value ratio indeed gives us a new angle to interpret the age effect. Consider a property of age 10 in 2012. For simplicity, let $\lambda=1, \delta=2 \%$, and $R_{2012}=50 \%$. Other things being equal, in 2013, aging by one year should depreciate the structure by $2 \%$ and the property by $1 \%$. However, the structure-toproperty value ratio may change. If $R_{2013}$ is $60 \%$, the property would actually depreciate by $1.2 \%$ - the greater depreciation was aquired as if the property had reached age 13 in one year. By contrast, if $R_{2013}$ is $40 \%$, the property would have looked as young as age 9 , as the property would only depreciate by $0.8 \%$. Therefore, the structure-to-property value ratio effectively breaks the linear relationship between age and time differences between sales, making it possible to separate the age effect from a repeat-sales index.

\footnotetext{
${ }^{6}$ Box-Cox transformation requires that the age variable is strictly positive.
} 
Table 1: Descriptive statistics of the repeat sales data in Hong Kong and Tokyo Hong Kong Island

\begin{tabular}{lcccc}
\hline \hline & $\begin{array}{c}\text { Price at } 1^{\text {st }} \text { sale } \\
(\text { HK\$ million })\end{array}$ & $\begin{array}{c}\text { Price at } 2^{\text {nd }} \text { sale } \\
(\text { HK\$ million) }\end{array}$ & $\begin{array}{c}\text { Age at } 1^{\text {st }} \text { sale } \\
\text { (quarters) }\end{array}$ & $\begin{array}{c}\text { Age at } 2^{\text {nd }} \text { sale } \\
\text { (quarters) }\end{array}$ \\
\hline Mean & 4.0267 & 4.7299 & 63.32 & 81.72 \\
Std.Dev. & 5.3257 & 6.9459 & 43.11 & 43.41 \\
Minimum & 0.101 & 0.101 & 1 & 2 \\
Maximum & 184.8 & 338 & 230 & 246 \\
\hline N=190,890 & & & & \\
Tokyo & & & Age at $1^{\text {st }}$ sale & Age at $2^{\text {nd }}$ sale \\
\hline \hline & Price at $1^{\text {st }}$ sale & Price at $2^{\text {nd }}$ sale & (quarters) & (quarters) \\
\hline Mean & $¥ 10,000$ & $¥ 10,000$ & 61.45 & 76.78 \\
Std.Dev. & $3,998.36$ & $3,402.43$ & 34.73 & 36.86 \\
Minimum & $3,180.38$ & $2,582.23$ & 1 & 2 \\
Maximum & $30,000.00$ & $68,000.00$ & 192 & 201
\end{tabular}

$\mathrm{N}=36,212$

\section{Estimated results of the age-adjusted repeat sales model}

\subsection{Data}

Housing sales in Hong Kong and Tokyo are used to estimate the repeat sales property price indices for the two cities. The time period runs from 1993Q1 to 2012Q2. 190,890 pairs of repeat sales in Hong Kong Island were collected from the EPRC database, and 36,212 pairs in the special 23 wards of Tokyo from a weekly magazine Shukan Jutaku Joho (Residential Information Weekly) published by Recruit Co., Ltd., which is one of the largest vendors of residential lettings information in Japan. ${ }^{7}$ Most of them are sales of condo units. The average sale price in Hong Kong is HK\$4-5 million (US\$600,000), whereas the average price in Tokyo is $30-40$ million (US\$400,000). The average building age in the repeat sales sample is similar in both places: about 15 years old in the first sale and 20 years old in the second sale. The descriptive statistics of their sale prices and building ages are shown in Table 1.

An important variable for the age- $\mathrm{R}$ model is $\mathrm{Rt}$, the ratio of construction cost to new property price. The average construction cost of a new residential building in Hong Kong is obtained from a major quantity surveying consultancy Rider Levett Bucknall (RLB), which publishes the RLB Hong Kong Cost Report every quarter. In Japan, the construction cost is obtained from the Ministry of Land, Infrastructure, Transportation and Tourism (MLIT).

Estimating the price of new property is problematic. New properties constitute only a small part of the existing stock and their prices can vary widely depending on their location and developer. This means the use of new property prices could introduce a lot of noise to $R_{t}$.

\footnotetext{
${ }^{7}$ Recruit Co., Ltd. provided us with information on contract prices for about 24 percent of all listings. Using this information, we were able to confirm that prices in the final week were almost always identical to the contract prices; see Shimizu et al. (2012).
} 
Table 2: Maximum likelihood estimates of the age effect

\begin{tabular}{ccc}
\hline & Hong Kong Island & Tokyo \\
\hline$\delta$ & $0.1029^{*}$ & $0.1035^{*}$ \\
$\lambda$ & $0.5547^{*}$ & $0.3212^{*}$ \\
Log-likelihood & $-19,185.82$ & $11,097.23$ \\
\hline
\end{tabular}

Note: * significant at the $1 \%$ level

We propose using the average property price in the entire housing market instead. Although the average property price is a biased estimate of the new property price due to aging, the bias is likely to be stable as new properties will be added to and old properties removed from the existing stock. With a large sample of transactions in the existing stock, the average age of transacted properties could remain more or less the same over time. Therefore, any underestimation from the use of all transacted properties could be compensated by a smaller $\delta$ in Equation 7. The model for estimating the age effect on property (rather than structure) is unaffected by this, but $\delta$ should be interpreted as a lower-bound estimate of the structure's depreciation rate.

The ratio of construction cost to average property price is shown in Figure 1. As expected, the properties in Hong Kong and Tokyo have a larger portion for land than structure. On average, the structure component only comprises $24 \%$ of the property value in Hong Kong and $37 \%$ in Tokyo. Note that these are upper-bound estimates because of the use of average prices of all transacted properties instead of just new property prices.

\subsection{Results of Age-R}

The maximum likelihood estimates of the parameters $\delta$ and $\lambda$ in Equation 7 are reported in Table 2, whereas the price index results will be reported separately later. With Box-Cox transformation, the marginal effect of age on log price is:

$$
E[\ln P(A)]=-\delta R_{t} A^{(\lambda-1)} \text { for } A>0
$$

As expected, $\delta$ is positive and significant at the $1 \%$ level, confirming that the age effect on property price is negative. Moreover, the magnitude of $\delta$ in Hong Kong is almost the same as that in Tokyo. At first sight, according to Equation 8, this can be interpreted as that the structure shares a similar initial depreciation rate in both cities. But as mentioned before, the magnitude of $\delta$ could be biased downward due to the use of average price of all transacted properties in estimating $R_{t}{ }^{8}$ So, $\delta$ alone cannot tell if the two cities really have a similar initial depreciation rate at the structure level; rather, $\delta$ has to be combined with $R_{t}$ in order to compare the depreciation rates at the property level.

While the magnitude of $\delta$ appears to be large, it is only the initial depreciation rate. Since $\lambda$ is smaller than 1 and significant, the depreciation pattern is confirmed to be non-linear:

\footnotetext{
${ }^{8}$ The downward bias in the $\delta$ estimate reinforces our prediction that the true $\delta$ should be positive.
} 
the structure depreciates more slowly as its age increases. We can examine the depreciation pattern of property by considering $\delta$ and $\lambda$ together. Assuming a property is worth $\$ 100$ at age 1 and the ratio of construction cost to property price stays at its average level $\left(R_{t}\right)$, the expected price of property at age $A$ is:

$$
E P(A)=\exp \left(\ln P(1)-\delta \bar{R}_{t}\right)
$$

Figure 2 plots the depreciation pattern calculated from Equation 9. Properties in Tokyo depreciate faster than those in Hong Kong initially, but the depreciation rate in Hong Kong picks up soon and the rates reach a "break-even" at about Age 20. Over 50 years, property value has depreciated by $29 \%$ in Hong Kong and $26 \%$ in Tokyo - by that time, the property value is mostly derived from the land. The cumulative depreciation can be converted to an average annual depreciation rate of $0.58 \%$ and $0.52 \%$, respectively. Bear in mind that these estimates are based on a constant structure-to-property value ratio. If the structure component gets larger (smaller), the depreciation rate will go up (down) accordingly.

The higher average depreciation rate in Hong Kong could be caused by under-maintenance of old buildings. In Hong Kong, the multiple ownership system for condominiums has created a lot of problemd in maintaining and managing the common areas (e.g. external walls, lifts, staircases, and lobbies). Court cases on building management issues and accidents due to building neglect are not uncommon. Legislation on mandatory building inspection and maintenance did not exist until recently. In contrast, buildings in Japan are generally better maintained because they have to withstand earthquakes and fulfill the relevant legal (Building Standard Law) and insurance requirements.

The coefficients of the time dummies from the Age-R model in Equation 7 provide us with the age-adjusted price indices for Hong Kong and Tokyo. As shown in Figures 3 and 4, our age- $\mathrm{R}$ indices are above the BMN indices in both Hong Kong and Tokyo, suggesting that property returns are higher after age adjustments. This result is intuitive, as the return captured by the BMN index is after depreciation.

Descriptive statistics of the indices are reported in Table 3. In Hong Kong, the mean return is $1.63 \%$ per quarter based on the age- $\mathrm{R}$ index and $1.56 \%$ based on the BMN index. The difference is $0.07 \%$ per quarter. In Tokyo, the mean return is $-0.67 \%$ per quarter based on the age- $\mathrm{R}$ index and $-0.97 \%$ based on the BMN index. The difference is $0.30 \%$ per quarter. The age adjustment is larger for Tokyo than Hong Kong because Tokyo has a larger component of structure relative to land. Moreover, the structure-to-property value ratio in Tokyo is, on average, larger in the second sales than the first sales, whereas the ratio in Hong Kong is smaller in the second sales. This implies a bigger age adjustment for the Tokyo housing market. 
Table 3: Descriptive statistics of the BMN and Age-R indices

\begin{tabular}{lcc}
\hline & Hong Kong Island & Tokyo \\
\hline Age-R & & \\
Mean return per quarter & $1.63 \%$ & $-0.67 \%$ \\
Return volatility per quarter & $5.26 \%$ & $1.71 \%$ \\
\hline BMN & & $-0.97 \%$ \\
Mean return per quarter & $1.56 \%$ & $2.18 \%$ \\
Return volatility per quarter & $7.05 \%$ & $0.30 \%$ \\
\hline $\begin{array}{l}\text { Age adjustment in property return } \\
\text { (per quarter) }\end{array}$ & $0.07 \%$ & $-0.53 \%$ \\
\hline \hline Hybrid & - & $2.21 \%$ \\
Mean return per quarter & - & $-0.52 \%$ \\
Return volatility per quarter \\
$\begin{array}{l}\text { Hedonic } \\
\text { Mean return per quarter } \\
\text { Return volatility per quarter }\end{array}$ & - & $2.06 \%$ \\
\hline $\begin{array}{l}\text { Diffremces in property return with Hybrid } \\
\text { (per quarter) }\end{array}$ & - & $-0.14 \%$ \\
$\begin{array}{l}\text { Diffremces in property return with Hedonic } \\
\text { (per quarter) }\end{array}$ & - & $-0.15 \%$ \\
\hline
\end{tabular}

\section{Comparison with other traditional models}

\subsection{Hybrid Model and Hedonic Model}

Here, we will compare the new Age-R index with indices based on the hedonic and hybrid models. As discussed in Introduction, the hedonic and hybrid models allow us to use a larger dataset comprising of both single and repeat sales, but they are more vulnerable to omitted variable bias. Therefore, the purpose of this section is to check whether the three models based on different assumptions and samples - will give similar estimates or not. If different methods share similar results, convergent validity is achieved. But it is not our purpose to judge which model is right or wrong.

In the Tokyo data, there is sufficient attribute data (characteristics) about condominiums to estimate a hedonic function. Thus, the hybrid method that was proposed to modify the repeat sales method proposed by Case and Quigley (1991) may also be applied. Here, to appraise the new Age-R proposed in the preceding section, we decided to compare the house price indices estimated by the hedonic method and the hybrid method using Tokyo data.

First, we will examine the hedonic model and hybrid model.

Hill, Knight, and Sirmans (1997) distinguished the time effect and age effect by refining Case and Quigley's (1991) hybrid method (hedonic and repeat sales method joint model estimation). The hedonic regression model is defined as: 


$$
y_{i t}=\ln P_{i t}+X_{i}^{\prime} \beta+\delta A_{i t}+\alpha_{t}+\epsilon_{i t}
$$

where $P_{i t}$ is the price of property $i$ at time $t ; X_{i}$ is a vector of property attributes excluding building age; $\beta$ is a vector of the implicit price of the attributes; is age effect; is $i$ th property age at time $t ; \alpha_{t}$ is the fixed time effect at time $t$; and $\epsilon_{i t}$ is a random error.

From sample $i=1, \ldots, N$, let us take as a property that is transacted twice. The repeat sales regression model may be written as follows:

$$
Y_{i}=y_{i t}-y_{i s}=\ln \frac{P_{i t}}{P_{i s}}=\tau_{i} \delta+\alpha_{t}-\alpha_{s}+v_{i} \quad\left(i=1,2, \ldots, N_{R}\right)
$$

Here, $\tau_{i}=A_{i t}-A_{i s}$ is the differential of the building age at time $s$ and time $t$. If all samples for (10) and (11) are pooled, the following regression model is obtained:

$$
\left(\begin{array}{c}
y \\
Y
\end{array}\right)=\left(\begin{array}{ccc}
X & A & d \\
0 & \tau & D
\end{array}\right)\left(\begin{array}{c}
\beta \\
\delta \\
\alpha
\end{array}\right)+\left(\begin{array}{c}
\epsilon \\
v
\end{array}\right)
$$

where $d$ and $D$ are the matrices of time dummy variables. A distinctive feature of this approach is that, by pooling a hedonic regression model and repeat sales regression model, the linear relationship between $\tau_{i}=A_{i t}-A_{i s}$ and $D$ is disrupted and makes it possible to estimate simultaneously the age effect $\delta$ and time effect $\alpha$.

The relationship between log price and the age term are linear in the hedonic equation of the hybrid model. To compare the age effects with the Box Cox transformed Age-R model, we estimate the hedonic regression model with the Box Cox transformed age term as follows:

$$
\ln P_{i t}=X_{i}^{\prime} \beta+\delta \frac{A_{i t}^{\lambda}-1}{\lambda}+\alpha_{t}+\epsilon_{i t}
$$

\subsection{Estimated results of Hybrid and Hedonic Model}

Let us compare the data collected for the hedonic estimate in Tokyo wards with the data used for estimation of repeat sales price (Table 4).

Although the number of repeat sales samples in the estimation period was 36,212 , hedonic samples increased to 375,374 , or more than about 10 times. That is, by the repeat sales method, only 1/10 of the transactions that occurred from 1993 to the 2nd quarter of 2012 could be utilized. If such a repeat sales sample is a typical random sample, it will be satisfactory, but if there is a bias in the sampling, there will be a bias in the index that is estimated.

First, looking at the average for prices, whereas this is $36,370,000$ yen in the data for the hedonic model, in the repeat sales sample, the price of the first transaction is $39,980,000$ yen, and that of the second is 34,020,000 yen. In other words, the average for the hedonic sample is between the average for the first transaction and the average for the second transaction. Looking at the number of post-construction years (A), whereas the average for the 
Table 4: Descriptive statistics of the repeat sales data and hedonic data

\begin{tabular}{llcccc}
\hline & & Mean & Std. Dev. & Min & Max \\
\hline Hedonic Sample & Price (¥10,000) & $3,637.92$ & $2,684.75$ & 185 & 112,000 \\
& Age (quarters) & 68.45 & 41.93 & 0 & 352 \\
\hline $\mathrm{N}=375,374$ & & & & & \\
\hline Repeat Sales Sample & Price at 1st sale (¥10,000) & $3,998.36$ & $3,180.38$ & 34 & 80,000 \\
& Price at 2nd sale (¥10,000) & $3,402.43$ & $2,582.23$ & 9 & 68,000 \\
& Age at 1st sale (quarters) & 61.45 & 34.73 & 1 & 192 \\
& Age at 2nd sale (quarters) & 76.78 & 36.86 & 2 & 201 \\
\hline
\end{tabular}

$\mathrm{N}=36,212$

hedonic sample is the 68th quarter, in the repeat sales sample, the average number of postconstruction years for the first transaction was the 61st quarter, and for the second, it was the 76th quarter. Thus, similarly to prices, the average number of post-construction years is between the average for the first transaction and the average for the second transactions. This means that there is no significant bias in the repeat sales sample.

Using the hedonic database thus constructed, we estimated the hedonic function together with the hybrid technique.

Here, comparing the aggregates for the hybrid model and the hedonic model based on Table 5, and comparing estimates, the coefficient for floor space is 1.098 for the hybrid method and 1.091 for the hedonic method, so there is not much difference. As for distance to the nearest station, this is -0.0071 by the hybrid method, and -0.009 by the hedonic method, whereas for times to the CBD (Center of the Business District), i.e., the time to Tokyo Station, it is -0.0257 for the hybrid method and -0.006 for the hedonic method.

\subsection{Comparison Age adjusted RS with traditional indexes}

Figure 5 shows the estimated price index computed from the hybrid model and hedonic model, compared with BMN repeat sales price index and Age-R. The hybrid price index and hedonic price index almost overlap; the new repeat sales price index (Age-R) follows a similar trend but is less volatile. In particular, the BMN repeat sales price index is strongly biased downwards, and by analogy, there is a depreciation bias that was clear from this series of studies. On the other hand, the Age-R proposed in this research, as compared to the BMN repeat sales price index, is largely shifted so that it approximates the hedonic price index and hybrid price index. As a result, the aggregation problem due to depreciation bias is largely improved. This result is extremely significant, although not as much as in the hybrid method.

However, even if we adjust for depreciation, a certain discrepancy remains between Age$\mathrm{R}$ and the hedonic/hybrid price index. This discrepancy may be due to the fact that the 
Table 5: Estimated results of Hedonic and Hybrid

\begin{tabular}{l|cc|cc}
\hline \multicolumn{1}{c|}{ Variable } & Coef. & $t$-value & Coef. & $t$-value \\
\hline & & & & \\
Age $(\delta)$ & -0.0046 & -219.809 & -0.0192 & -72.135 \\
Box Cox $(\lambda)$ & - & - & 0.6353 & 182.680 \\
Log (Floor Space) & 1.1021 & 568.018 & 1.0890 & 1330.660 \\
Distance to Nearest Station & -0.0071 & -42.0458 & -0.0089 & -121.360 \\
$\quad$ Distance to Tokyo Sta. & -0.0257 & -56.8187 & -0.0058 & -41.792 \\
Building Construction Dummy & & & Yes & \\
$\quad$ Ward Dummy & Yes & & Yes & \\
Time Dummies & Yes & & Yes & \\
$\quad$ const. & 4.860 & 416.450 & 5.041 & 659.798 \\
\hline Number of obs. & 108,969 & & 375,374 & \\
R-squared & 0.998 & & 0.889 & \\
Adjusted R-squared & 0.998 & & 0.889 & \\
S.E. of regression & 0.189 & & 0.182 & \\
Log likelihood & 26915.9 & & 106200.0 &
\end{tabular}

samples were different or the choice of variables in the hedonic equation. In other words, although depreciation can be controlled for in both the Age-R and hedonic/hybrid models, the potential sample selection bias inherent in the repeat sales price method and the potential omitted variable bias in the hedonic-based method cannot be resolved.

Moreover, if we compare the magnitudes of the depreciation bias and sample selection bias, the bias due to depreciation is much larger. In other words, the Age-R evidently resolves the major part of the bias inherent in the repeat sales price method.

Next, Figure 6 compares the age indexes using aggregate parameters that correspond to the number of post-construction years (A) estimated in the hybrid model, hedonic model, and the Age-R proposed in this research. Figure 7 and Table 6 show the marginal effects.

Table 6: Average depreciation rate

\begin{tabular}{c|c|ccc} 
& $\begin{array}{c}\text { Age adjusted RS } \\
\text { (HK) }\end{array}$ & $\begin{array}{c}\text { Age adjusted RS } \\
\text { (TKO) }\end{array}$ & $\begin{array}{c}\text { Hedonic } \\
\text { (TKO) }\end{array}$ & $\begin{array}{c}\text { Hybrid } \\
\text { (TKO) }\end{array}$ \\
\hline over 50 yrs & $-0.58 \%$ & $-0.52 \%$ & $-1.14 \%$ & $-1.18 \%$ \\
over 40 yrs & $-0.65 \%$ & $-0.59 \%$ & $-1.29 \%$ & $-1.27 \%$ \\
\hline $0-10 \mathrm{yrs}$ & $-1.09 \%$ & $-1.22 \%$ & $-2.36 \%$ & $-1.51 \%$ \\
$10-20 \mathrm{yrs}$ & $-0.64 \%$ & $-0.53 \%$ & $-1.47 \%$ & $-1.51 \%$ \\
$20-30 \mathrm{yrs}$ & $-0.51 \%$ & $-0.38 \%$ & $-1.23 \%$ & $-1.51 \%$ \\
$30-40 \mathrm{yrs}$ & $-0.44 \%$ & $-0.30 \%$ & $-1.09 \%$ & $-1.51 \%$ \\
$40-50 \mathrm{yrs}$ & $-0.40 \%$ & $-0.26 \%$ & $-1.00 \%$ & $-1.51 \%$ \\
\hline
\end{tabular}


As can be seen from Figure 1, the proportion accounted for by house construction costs in Japan was about 20\% in 1991 during the country's economic bubble years, but recently it increased to about 35\%. Considering that the average between 1991-2012 is also about $33 \%$, it may be said that the average for 2012 is around the average level for the last 20 years. In other words, considering there is no depreciation of land, regardless of how much house prices have depreciated, the maximum value of this depreciation is $35 \%$, and $65 \%$ of the price has been maintained.

Looking at Figure 6 from this assumption, the result estimated from the hybrid model and the hedonic model is that $65 \%$ of house prices are factored in 15 years post-construction, and they will be at the $40 \%$ level at 50 years post-construction. This means, since land suffers no depreciation, that the value of property is estimated to be negative. On the other hand, looking at the result estimated from Age-R, the value at 50 years post-construction is $70 \%$, so that although it depreciates close to $65 \%$ that includes land values, a small property value remains.

From this result, it is clear that if we calculate the rate of depreciation by the hedonic or hybrid method taking land and property together, it will be largely over-estimated.

Comparing the marginal effects for depreciation (Figure 7, Table 6), in the 50 year-average, the rates of depreciation estimated from the hedonic method and hybrid method are about twice the rate of appreciation estimated from the new Age-R method proposed here, and the discrepancy becomes larger, the larger the number of post-construction years.

In section 3, we suggested that property returns are higher after age adjustments.

In addition to this analysis, we compared age $\mathrm{R}$ with hybrid and hedonic indexes in Tokyo. The mean return of Age $\mathrm{R}$ is smaller than 0.14 and $0.15 \%$ than that of Hybrid and Hedonic indexes(Table 3). Age $\mathrm{R}$ is overcoming depreciation problem in estimating Repeat Sales regression, while the returns from the hedonic and hybrid indexes are higher probably due to the over-adjustment of depreciation as discussed above.

\section{Conclusion}

Since real estate is heterogeneous and infrequently traded, the repeat sales model has become a popular method to estimate a property price indexes. However, the model fails to adjust for depreciation, as age and time between sales have an exact linear relationship. This paper proposes a new method to estimate an age-adjusted repeat sales index by decomposing property value into land and structure components. As depreciation is more relevant to the structure than land, the property's depreciation rate should depend on the relative size of land and structure. The larger the land component, the lower the depreciation rate of the property. Based on housing transactions data from Hong Kong and Tokyo, Hong Kong has a higher depreciation rate (assuming a fixed structure-to-property value ratio), while the resulting age adjustment is larger in Tokyo because its structure component has grown larger from the first to second sales.

To evaluate the Age-R proposed here, we input the Tokyo data into both the hybrid model 
and the hedonic model, and then compared the estimated price indexes. This comparison revealed that newly proposed Age-R cancels out the inherent depreciation problem of the repeat sales model. Although the sample selection bias of the repeat sales model is expected to remain, the magnitude of this problem was shown to be far smaller than that of the bias resulting from depreciation. We also compared the estimated depreciation rate here with the depreciation rate estimated by using the hedonic model and hybrid model. Housing consists of land and structure, but the depreciation that occurs only applies to the structure. When the hedonic model and hybrid model are used to estimate the depreciation rate of the combined price of land and structure, the study revealed that as the structure value becomes negative over a specified period of time, depreciation cuts into the land value. This was not a realistic result. Essentially, this result reiterates the importance of separating land and structure when attempting to calculate the depreciation of housing, just as was proposed by Diewert and Shimizu (2013). Nevertheless, in regions where the repeat sales model, and not the hedonic model, can be applied, the use of the Age- $\mathrm{R}$ is considered to be a valid method for calculating an appropriate depreciation rate.

In the "Handbook of Residential Property Indexes" that Eurostat began to distribute in $2012,{ }^{9}$ the hedonic model is recommended for estimating price indexes. However, when attempting to estimate the real estate price index for the purpose of official statistics, there will be many countries where the hedonic method cannot be applied due to existing restrictions on data. This is because a variety of data about the characteristics of housing must be collected in order to apply the hedonic method. In these countries, the depreciation bias will be a major problem when using the repeat sales model to estimate the price index. This fact is not only noted in the Eurostat handbook, but has also been made clear in this paper.

In conclusion, we believe that the new Age-R proposed in this paper is a valid means for solving the problem of depreciation bias.

\section{References}

[1] Bailey, M. J., R. F. Muth, and H. O. Nourse. (1963). A Regression Model for Real Estate Price Index Construction, Journal of the American Statistical Association 58, 933-942.

[2] Case, B and J. M. Quigley (1991), The dynamics of real estate prices, Review of Economics and Statistics 22, 50-58.

[3] Chau, K.W., S. K. Wong, and C. Y. Yiu (2005). Adjusting for Non-Linear Age Effects in the Repeat Sales Index, Journal of Real Estate Finance and Economics 31:2, 137-153.

[4] Diewert, W. E (2007), The Paris OECD-IMF Workshop on Real Estate Price Indexes: Conclusions and Future Directions. Discussion Paper 07-01, Department of Economics, University of British Columbia, Vancouver, Canada, V6T1Z1.

\footnotetext{
${ }^{9}$ RPPI Handbook is available from the following website: http://epp.eurostat.ec.europa.eu/portal/page/portal/hicp/methodology/l
} 
[5] Diewert, W.E., J. de Haan and R. Hendriks (2011). "Hedonic Regressions and the Decomposition of a House Price index into Land and Structure Components," Discussion Paper 11-01, Department of Economics, University of British Columbia, Vancouver, Canada, V6T1Z1. Forthcoming in Econometric Reviews.

[6] Diewert, W. E. and C. Shimizu (2013). "A Conceptual Framework for Commercial Property Price Indexes," Discussion Paper 13-11, Vancouver School of Economics, University of British Columbia.

[7] Englund, P., J. M. Quigley, and C. L. Redfearn (1998). Improved Price Indexes for Real Estate: Measuring the Course of Swedish Housing Prices, Journal of Urban Economics 44, 171-196.

[8] Gatzlaff, D. H. and D. R. Haurin (1997). "Sample Selection Bias and Repeat-Sales Index Estimates," Journal of Real Estate Finance and Economics, 14 (1), 33-50.

[9] Gatzlaff, D. H. and D. R. Haurin (1998). "Sample Selection and Biases in Local House Value Indices," Journal of Urban Economics, 43(2), 199-222.

[10] Hill, R. C., J. R. Knight and C. F. Sirmans (1993) "Estimation of Hedonic Housing Price Models Using non Sample Information: A Montecarlo Study," Journal of Urban Economics, 34(3), 319-346.

[11] Karato, K, O. Movshuk and C. Shimizu (2010). "Semiparametric Estimation of Time, Age and Cohort Effects in A Hedonic Model of House Prices," Faculty of Economics, University of Toyama, Working Paper No. 25

[12] Palmquist, R. B (1980). Alternative Techniques for Developing Real Estate Price Indexes, Review of Economics and Statistics 66, 394-404.

[13] Shimizu, C., K. G. Nishimura and T. Watanabe (2010). "House Prices in Tokyo A Comparison of Repeat-sales and Hedonic Measures-," Journal of Economics and Statistics, 230 (6), 792-813

[14] Shimizu, C., K.G. Nishimura and T. Watanabe (2012). "House Prices from Magazines, Realtors, and the Land Registry," Property Market and Financial Stability, BIS Papers No.64, Bank of International Settlements, March 2012, 29-38.

[15] Thorsnes, P. (1997). "Consistent Estimates of the Elasticity of Substitution between Land and Non-Land Inputs in the Production of Housing," Journal of Urban Economics 42, 98-108. 


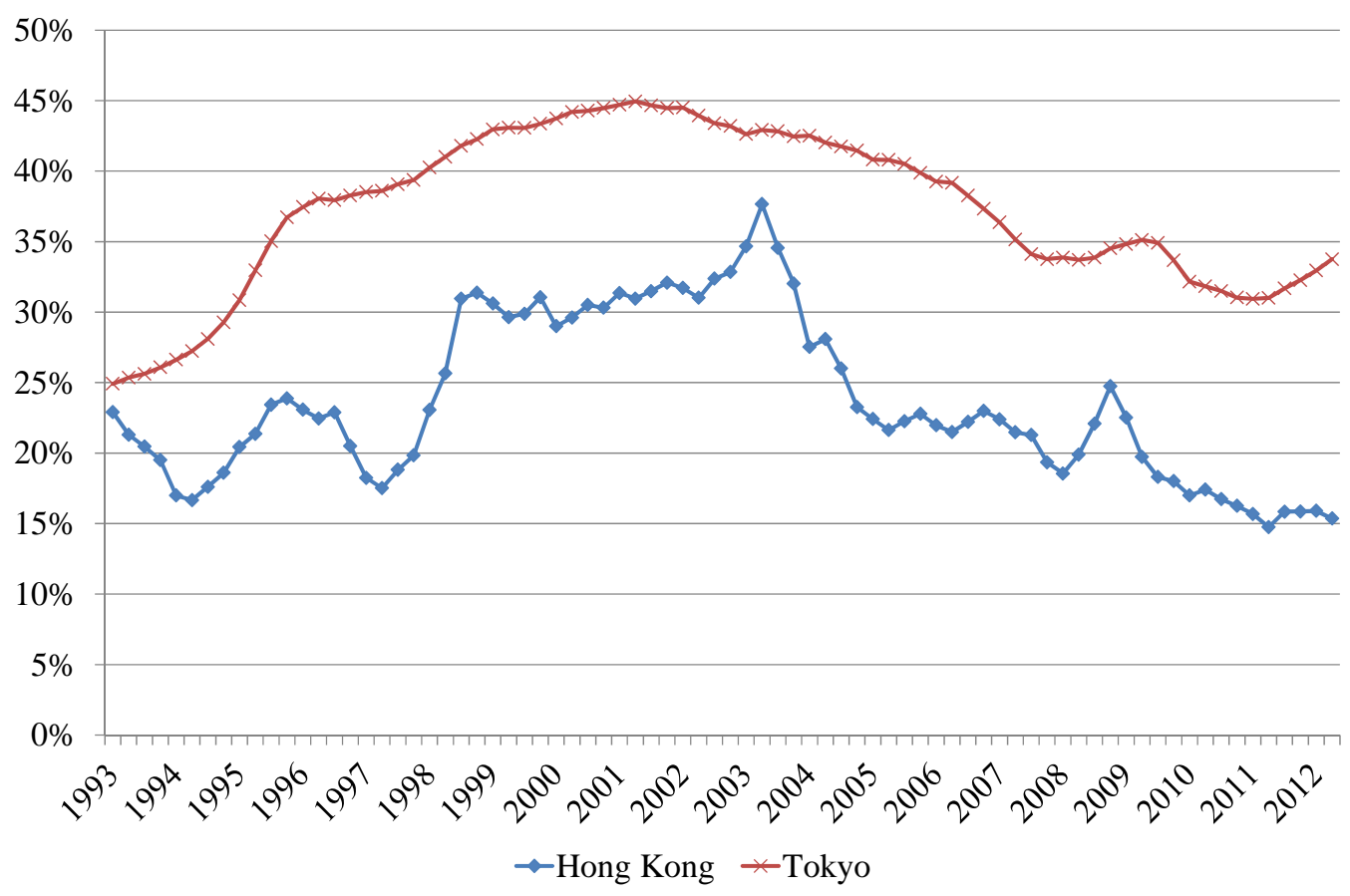

Figure 1: Ratio of construction cost to average property price

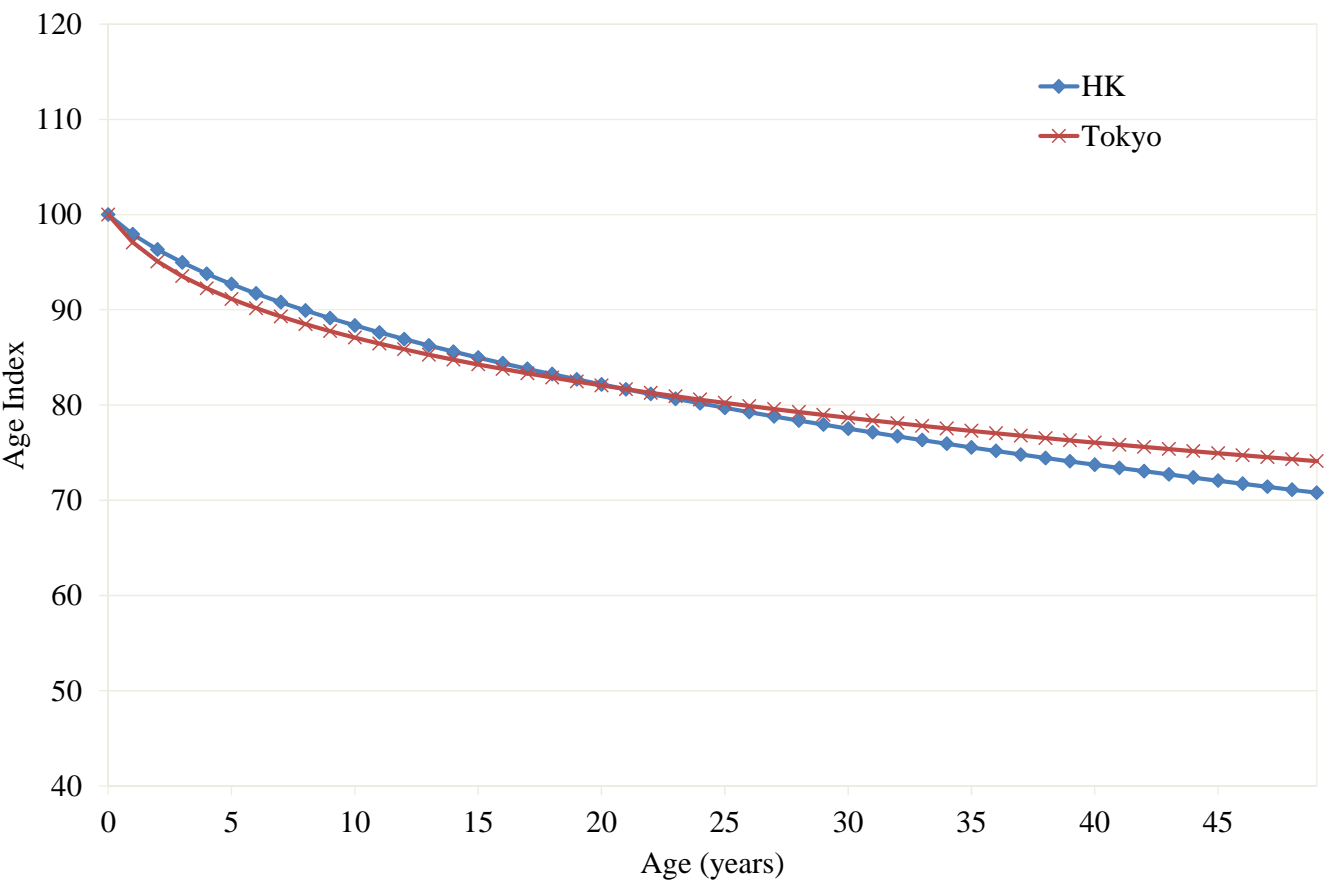

Note: A constant structure-to-property value ratio is assumed

Figure 2: Property depreciation pattern in Hong Kong (HK) and Tokyo 


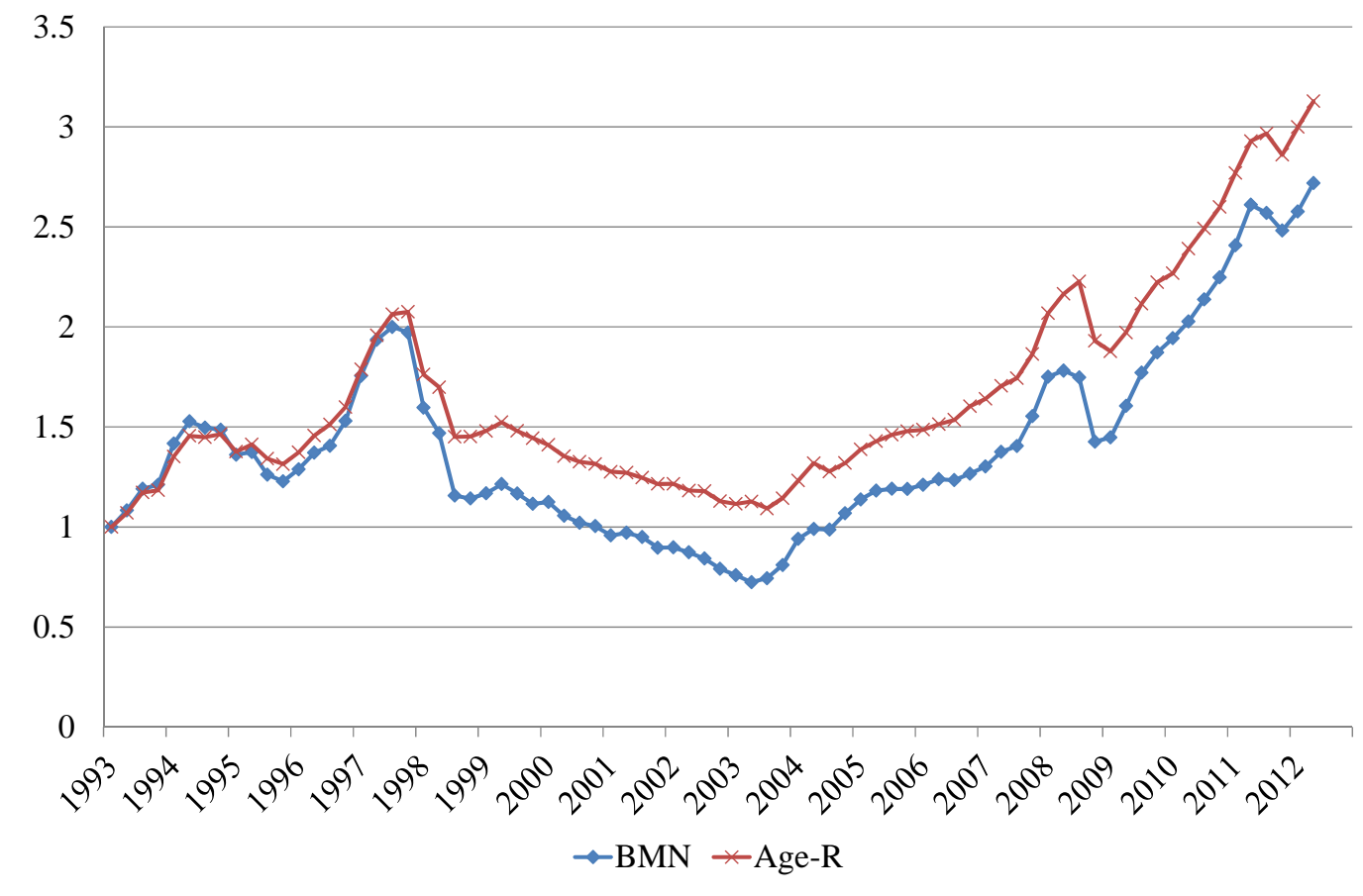

Figure 3: Hong Kong Island's repeat sales indices

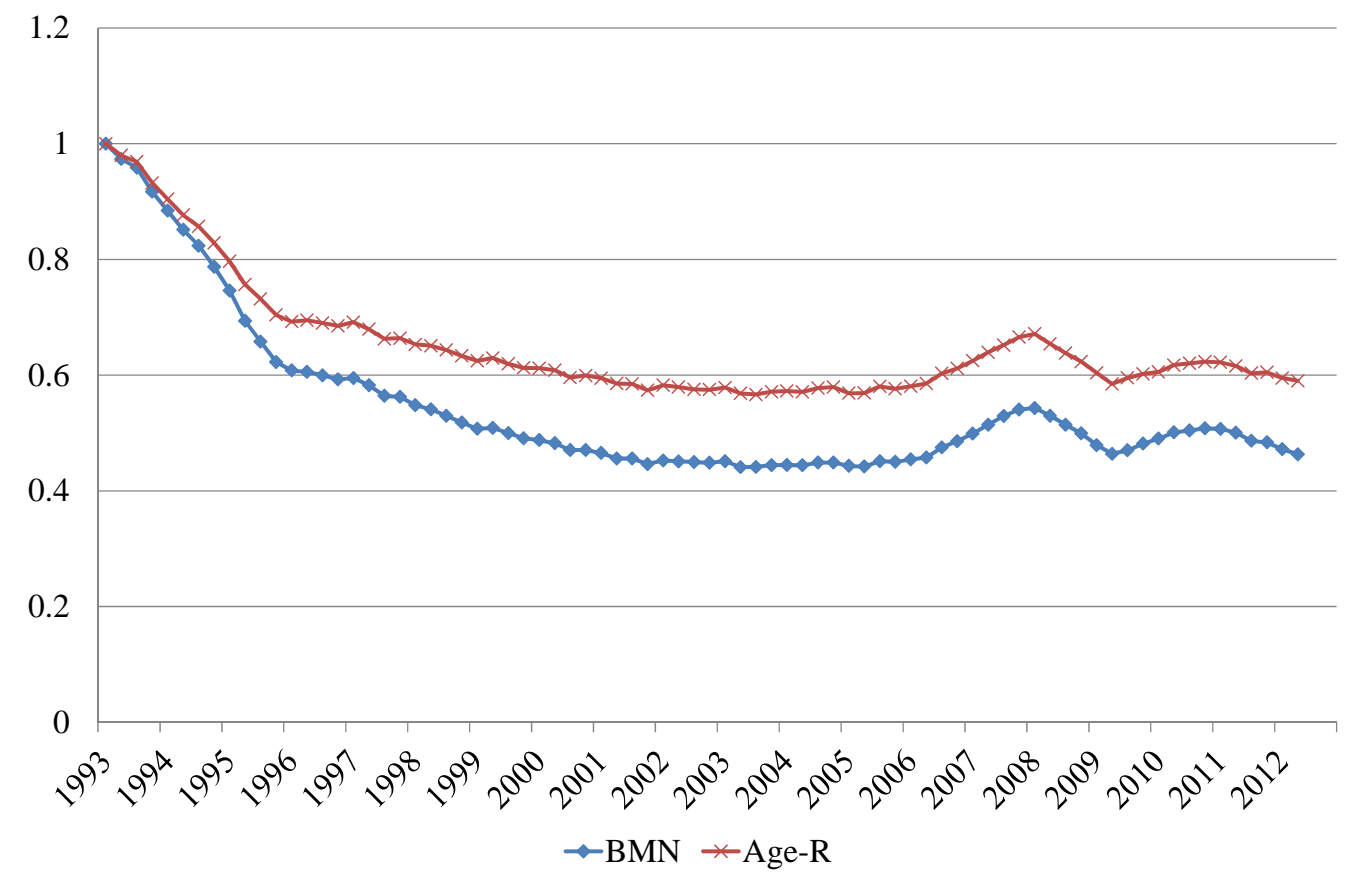

$\mathrm{BMN}$ is the traditional repeat sales index; Age- $\mathrm{R}$ is the age-adjusted repeat sales index based on Equation 7

Figure 4: Tokyo's repeat sales indices 


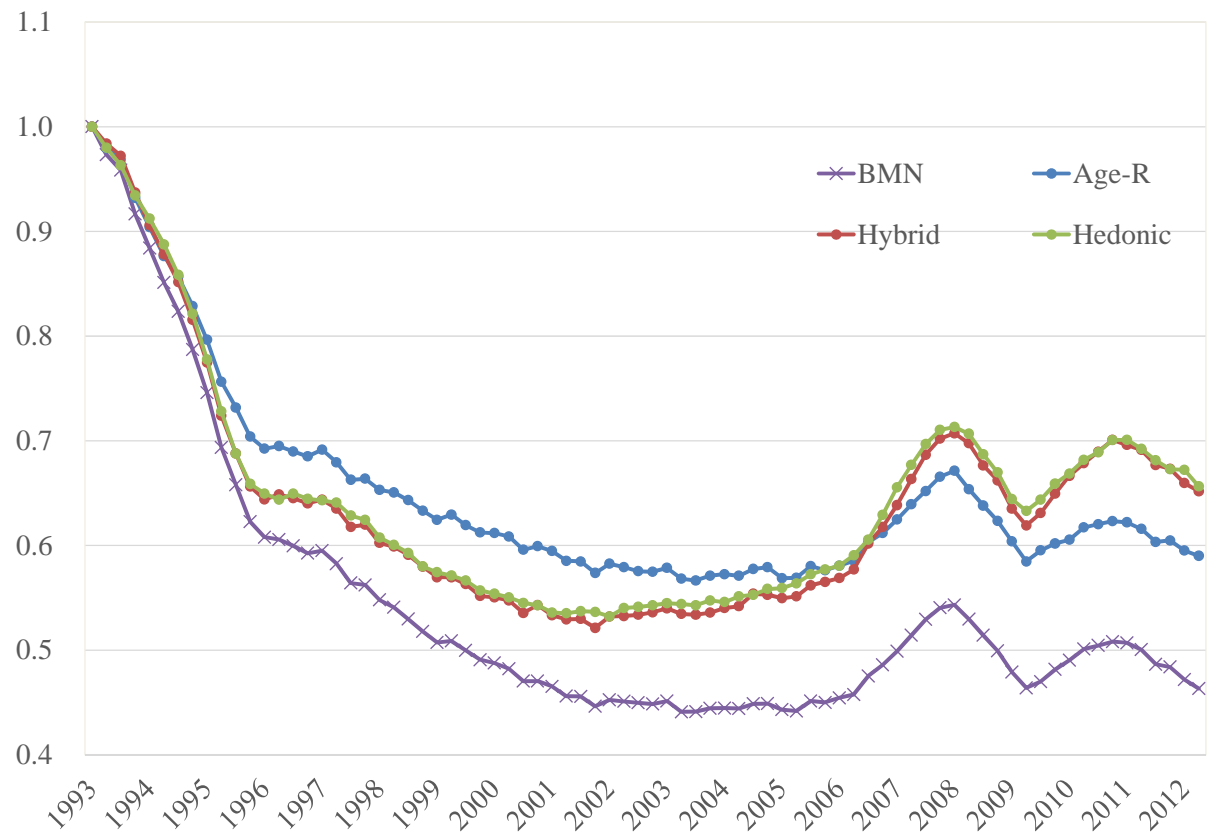

Figure 5: Comparison of BMN, Age-R, Hedonic and Hybrid property price indexes in Tokyo 


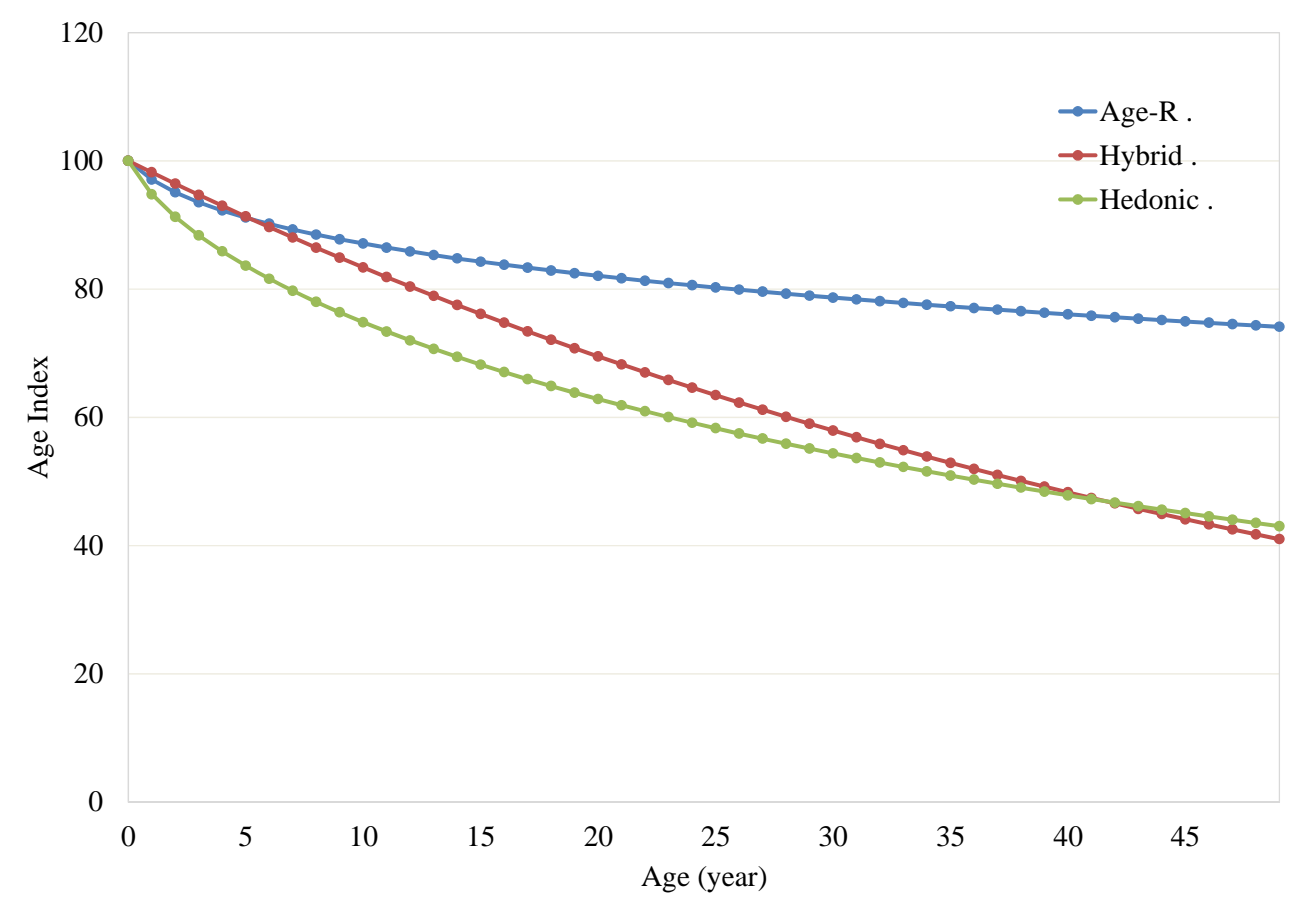

Figure 6: Comparison of Age-R, Hedonic and Hybrid Age indexes

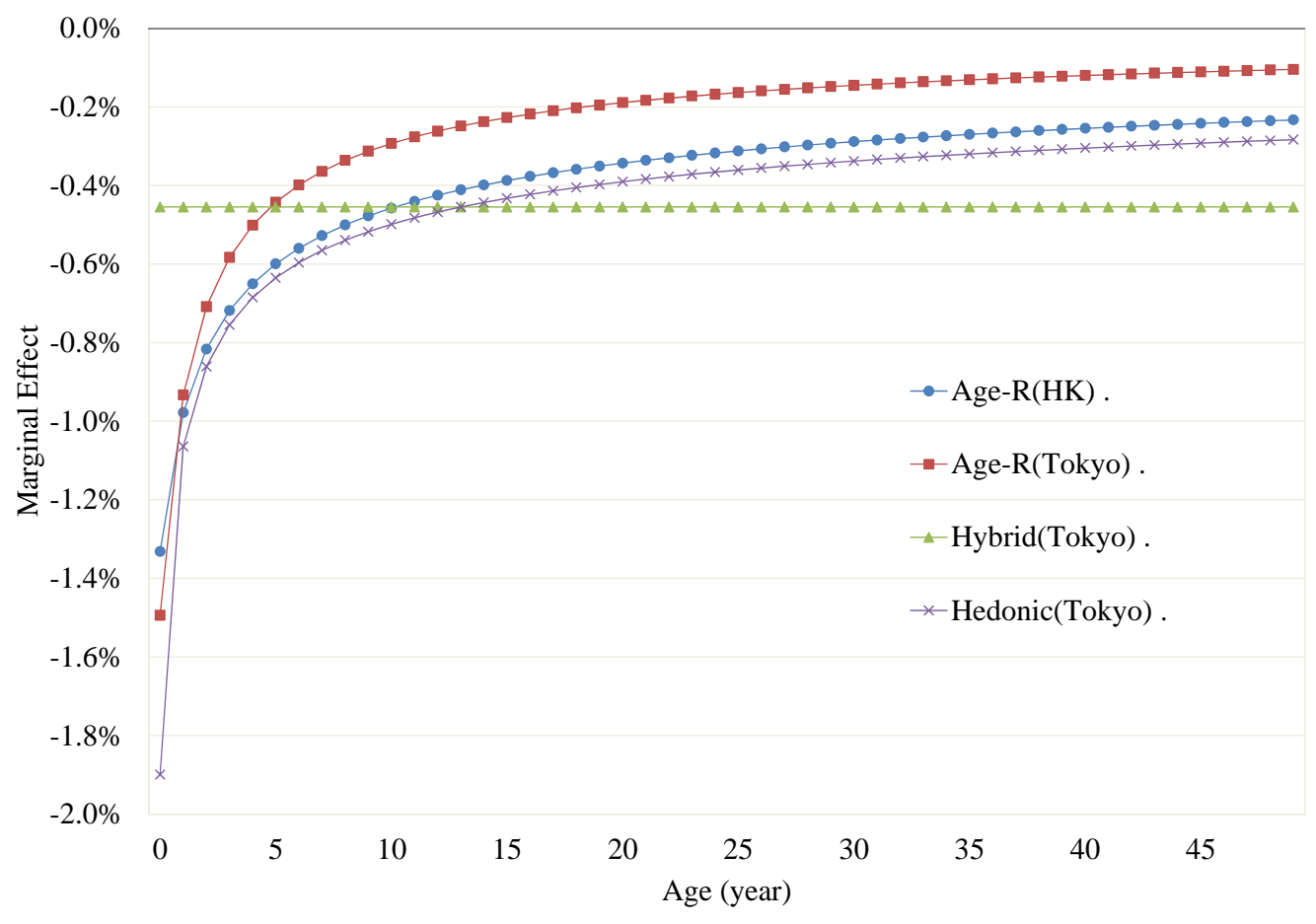

Figure 7: Marginal effect of depreciation rate 

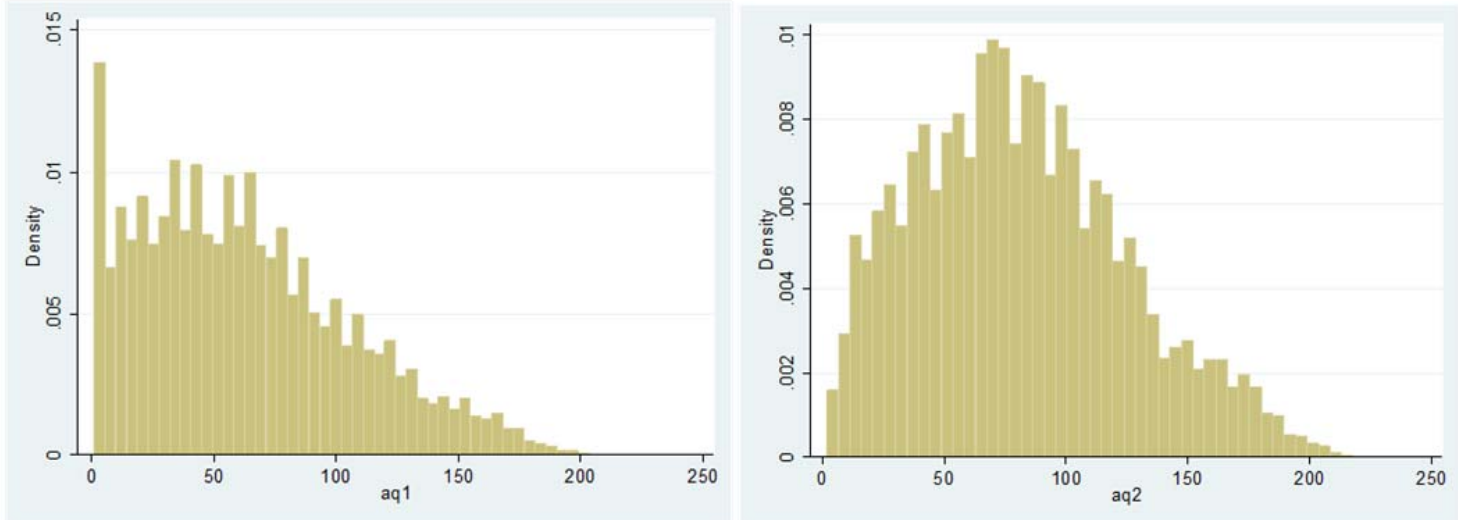

Histogram of Age (Hong Kong, 1st Transaction, quarter)

Histogram of Age (Hong Kong, 2nd Transaction, quarter)
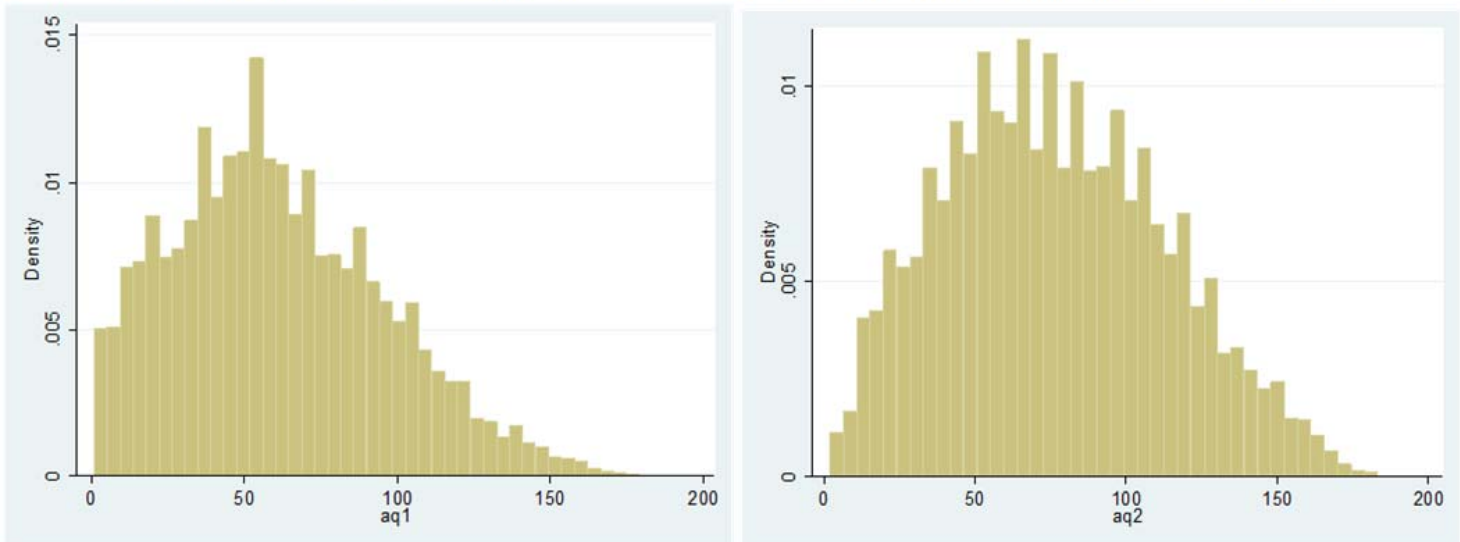

Histogram of Age (Tokyo, 1st Transaction, quarter)

Histogram of Age (Tokyo, 2nd Transaction, quarter)

Appendix: Histogram of Age of Building in Hong Kong and Tokyo 